\title{
Organising a Web-Based Conference
}

\author{
Krish Lakshman ${ }^{1}$ \\ Received: 9 November 2020 / Accepted: 3 December 2020 / Published online: 13 January 2021 \\ (C) Association of Surgeons of India 2021
}

\begin{abstract}
Covid-19 pandemic with its restrictions on social interactions including the need for physical distancing has had a profound effect on surgical education. Several innovative ideas have been put into action by surgeons to overcome this limitation. Holding online conferences is one such innovation. We present here the basic template for holding a cost-effective online conference based on the experience gained from a successful and well-received midterm conference of the Karnataka State Chapter of the Association of Surgeons of India.
\end{abstract}

Keywords Web-based conference $\cdot$ Surgical education $\cdot$ Webinars $\cdot$ Online conference

\section{Introduction}

Covid-19 and the associated requirement of physical distancing has had a profound impact on surgical education. The surgical fraternity has adapted very well to this new situation by having various teaching activities on a virtual video conferencing platform. Conducting a conference is one such activity [1-3].

The Karnataka State Chapter of Association of Surgeons of India (KSCASI) conducted a midterm conference. This event was very well received. We share with the readers the general principles and skills involved in conducting such a conference.

We decided to use the in-house manpower and IT knowledge to complete the project with no professional IT involvement. This is possible with some basic knowledge in using google forms (for gathering information), docs (word processing), slides (for presentations) and sheets (spreadsheets) and mail merging. The Google platform provides unlimited free storage when files are stored in the google document format. A practical knowledge of using a videoconferencing platform is a necessity. Our only cost was Rs. 15,000 towards the use of the video conferencing platform. We conducted the

Krish Lakshman

klakshman58@gmail.com

1 Department of General Surgery, Shanti Hospital and Research Centre, 307, 40th Cross, 8th Block, Jayanagar, Bangalore 560070, India conference for 3 days between 3 pm and 9 pm with 350 registrants and 260 presentations.

The planning and execution can be considered under the following headings:

1. Basic planning

2. Advanced and specific planning

3. Execution

A short communication like this precludes a detailed discussion. Hence, the following link is given for interested readers to have access to a report on the event where these issues are discussed in detail: https://docs.google.com/ d ocument/d/14fT__ayuhLK YwekGFzz1 i Y OwoIoBQfkNg3ZFUu9ppA/edit?usp=sharing.

\section{Basic Planning}

We decided on the 'Zoom' platform for its ease of access, affordability and familiarity with our target audience. We had 3 screens with unlimited access to 500 participants in each screen.

We used 3 basic forms for gathering information. These included the registration form, the abstract submission form and the permission form for using the submitted material on our website.

We set a deadline for all the presentations to be submitted 2 weeks in advance. This facilitated the hyperlinking of these presentations to the programme sheet. This is a requirement to 
make sure that this large number of presentations run smoothly.

Organisers running presentations have several advantages:

1. They can run the presentations from computers with assured capacity and broadband connections.

2. It takes away the time lag that occurs between presenters having to share their screens.

3. Even if the computer or the connection of the presenter fails, he can use his phone to just give the audio inputs during the presentation.

4. And, very importantly, the organisers can control the timing of the presentation. If someone overshoots his time, they can be forced to go to the conclusion slide and finish the presentation.

\section{Advanced Planning}

This consisted of detailed communication through mail merging - the google sheets can be easily merged with Gmail. Various aspects of the requirements, duties and responsibilities of participants were communicated this way. The detailed programme was shared through email.

\section{Execution}

The crucial part was to have young volunteer surgeons as screen managers to actually run the programme. Liaison with the large number of presenters was done through WhatsApp groups. Training of the various groups was done through several 'Zoom' sessions and 'Dry' runs.

\section{Conclusion}

With some working knowledge of google productivity applications and video conferencing, large online conferences can be held with very little expenditure. The low-cost factor may well make this the preferred method for holding conferences.

Acknowledgements I would like to thank the screen managers Drs. Nishant, Tejaswi, Vinay, Niranjan, Wasim and Hosni whose pivotal role ensured success of the conference.

I would like to thank the office bearers of KSCASI for giving me the opportunity to undertake this activity.

I would like to thank the scientific committee of KSCASI for their unconditional support.

Data Availability All the data will be provided on request.

\section{Compliance with Ethical Standards}

Ethics Approval Not required.

Consent to Participate Not applicable.

Consent for Publication Not applicable.

\section{References}

1. Patel NM, Khajuria A, Khajuria A (2020) Utility of a webinar to educate trainees on UK core surgical training (CST) selection - a cross sectional study and future implications amidst the COVID-19 pandemic. Ann Med Surg 59:35-40

2. Mishra D, Nair AG, Gandhi RA, Gogate PJ, Mathur S, Bhushan P, Srivastav T, Singh H, Sinha BP, Singh MK (2020) The impact of COVID-19 related lockdown on ophthalmology training programs in India - outcomes of a survey. Indian J Ophthalmol 68:999-1004

3. El Hawary H, Salimi A, Alam P et al (2020) Educational alternatives for the maintenance of educational competencies in surgical training programs affected by the COVID-19 pandemic. J Med Educ Curric Dev 7:1-3

Publisher's Note Springer Nature remains neutral with regard to jurisdictional claims in published maps and institutional affiliations. 